\title{
İletken İplik Alımında Etkili Kriterler Arasındaki İlişkilerin DEMATEL Yöntemi İle Belirlenmesi
}

\author{
Münire Sibel Çetin ${ }^{1 *}$, Duygu Erdem ${ }^{2}$ \\ 1 Bağımsız Araştırmacı, İzmir, Türkiye (ORCID: 0000-0003-1875-3302) \\ 2 Selçuk Üniversitesi, Sanat ve Tasarım Fakültesi, Moda Tasarımı Bölümü, Konya, Türkiye (ORCID: 0000-0002-8277-3589)
}

(İlk Geliş Tarihi 17 Temmuz 2019 ve Kabul Tarihi 18 Eylül 2019)

(DOI: 10.31590/ejosat.593034)

ATIF/REFERENCE: Çetin, M. S. \& Erdem, D. (2019). İletken İplik Alımında Etkili Kriterler Arasındaki İlişkilerin DEMATEL Yöntemi İle Belirlenmesi. Avrupa Bilim ve Teknoloji Dergisi, (17), 152-160.

$\ddot{O} z$

Teknolojik gelişmelerin artı̧̧ıla birlikte teknolojik ürünler hayatımızın her saniyesinde ihtiyaç haline gelmiştir. Bu ihtiyaç doğrultusunda teknolojinin tekstil ürünleriyle birleştirilmesi ile giyilebilir teknolojiler ortaya çıkmıştır. Giyilebilir teknolojiler sağladıkları kolaylıklar sayesinde sağlık sektörü, askeri uygulamalar ve eğlence sektörü gibi farklı alanlarda kullanılır hale gelmiştir. Giyilebilir teknoloji kavramından yola çıkılarak geliştirilen bir diğer konsept elektronik tekstiller konseptidir. Elektronik tekstil üretiminde elektronik bileşenlerin tekstil ürünlerine dahil edilmesi ya da tekstil ürünlerinin iletken hale getirilerek bu bileșenlerin doğrudan tekstil formunda üretilmesi üzerinde durulmaktadır. İletken tekstil yapıları elde etmek için iletken iplikler, iletken kumaşlar, iletken kaplamalar ve iletken yapıştırıcılar gibi farklı malzemelerden faydalanılabilir. $\mathrm{Bu}$ iletken malzemeler arasında iletken iplikler gerek bir doku ya da yüzey oluşturmak amacıyla gerekse bağlantı yollarında kullanılmak üzere çokça tercih edilen iletken tekstil ürünlerinden biridir. Bu çalışma kapsamında, öncelikli olarak iletken iplik alımında etkili olan kriterler belirlenmiştir. Bu kriterler; metal oranı, iletkenlik, esneklik, biyouyumluluk, mekanik dayanım, yıkanabilirlik, makinede işlenebilirlik ve fiyat kriteridir. Ardından iletken iplik alım işleminde etkili 10 uzmandan, belirlenmiş olan kriterleri, alım işlemindeki önem seviyesine göre puanlaması istenmiş̧tir. Toplanan veriler çok kriterli karar verme yöntemlerinden DEMATEL yöntemi kullanılarak değerlendirilmiştir. Yapılan değerlendirmeler sonucunda kriter ağılıkları öncelik derecesine göre sıralandığında; \%17 kriter ağırlığı ile makinede işlenebilirlik sistem içerisindeki en önemli kriter olmuştur. Bu kriteri sırasıyla iletkenlik $(\% 16,86)$, biyouyumluluk $(\% 13,66)$, metal oranı $(\% 11,60)$, mekanik dayanım $(\% 11,54)$, fiyat $(\% 10,77)$ ve esneklik $(\% 10,69)$ kriterleri takip etmektedir. En önemsiz kriter ise \%7,8 ağıllı̆̆ ile yıkanabilirlik kriteridir. A $\breve{g}$ yapısı incelenerek kriterlerin birbirini etkileme durumlarına bakıldığında; en çok kriteri etkileyen makinede işlenebilirlik kriteri iken bu kriter hiçbir kriterden etkilenmemektedir. Yıkanabilirlik kriterinin hiçbir kriter üzerinde etkisi yokken, tüm kriterlerden etkilendiği sonucuna ulaşılmıştır.

\section{Determination of the Relationship Between Effective Criteria in Conductive Yarn Purchase using DEMATEL Method}

\begin{abstract}
With the increase of technological developments, technological products have become a necessity in every second of our lives. Because of this need, wearable technologies have emerged by combining technology with textile products. Wearable technologies are used in different fields such as healthcare, military applications and entertainment by means of their convenience. Another concept developed from the term of wearable technology is the concept of electronic textiles. In the production of electronic textiles,
\end{abstract}

\footnotetext{
* Sorumlu Yazar: Bağımsız Araştırmacı, İzmir, Türkiye, ORCID: 0000-0003-1875-3302, muniresibelcetin@ gmail.com
} 
electronic components are included in textile products or these components are directly produced in textile forms by making the textile products conductive. Different materials such as conductive yarns, conductive fabrics, conductive coatings and conductive adhesives can be utilized to obtain conductive textile structures. Among these conductive materials, conductive yarns are one of the most preferred conductive textile products, either for the purpose of forming a texture or surface, or for use in connection paths. In this study, the criteria which are effective in the purchase of conductive yarn have been determined firstly. These criteria are; metal ratio, conductivity, flexibility, biocompatibility, mechanical strength, washability, usability in the machine for production and price criteria. Then, it was requested from 10 experts, who purchases conductive yarn in their company, to score the determined criteria according to the importance level in the yarn purchasing process. Collected data were evaluated using DEMATEL method which is one of the multi criteria decision making methods. As a result of the evaluations, when the criteria weights are sorted according to importance level; usability in the machine for production is the most important criterion in the system with $17 \%$ criterion weight. This criterion is followed by conductivity $(16.86 \%)$, biocompatibility $(13.66 \%)$, metal ratio (11.60\%), mechanical strength (11.54\%), price $(10.77 \%)$ and flexibility $(10 \%, 69)$ criteria, respectively. The least important criterion is the washability criterion with a weight of $7.8 \%$. When the network structure and interplay of criteria are examined, usability in the machine for production criterion is the most influencing criterion whereas this criterion is influenced by no criterion. It was concluded that while the washability criterion had no effect on any criterion, it was affected by all criteria.

Keywords: Conductive yarn, DEMATEL, Multi criteria decision making methods.

\section{Giriş}

Ardı ardına gelen ekonomik krizlerde ayakta kalabilmek için tekstil sektörünün katma değeri yüksek ürünlere yönelmesi gerekmiş, özel ihtiyaçlara çözüm sunan ileri bilgi ve beceri gerektiren tekstil ürünlerinin üretimine başlanmıştır. Sanayi devrimi sonrasında teknolojik gelişmelerin hızlı bir biçimde artış göstermesi ve araştırmacıların disiplinler arası çalışmalara yönelmeleri yenilikçi ürünlerin ortaya çıkmasına olanak sağlamaktadır. Disiplinler arası çalışmalar sonucu ortaya çıkan en önemli teknolojik gelişmelerden birisi de giyilebilir teknolojilerdir (Yetmen, 2017).

Giyilebilir teknolojiler sağladıkları kolaylıklar sayesinde sağlık sektörü, askeri uygulamalar ve eğlence sektörü gibi farklı alanlarda kullanılır hale gelmiştir (Lukowicz, 2008). Giyilebilir teknoloji kavramından yola çıkılarak geliştirilen bir diğer konsept elektronik tekstiller konseptidir (Wagner ve ark., 2002). Elektronik tekstil üretiminde sensörler, mikroişlemciler gibi elektronik bileşenlerin tekstil ürünlerine dahil edilmesi ya da tekstil ürünlerinin iletken hale getirilerek bu bileşenlerin doğrudan tekstil yapıları formatında üretilmesi üzerinde durulmaktadır. İletken tekstil yapıları elde etmek için iletken iplikler, iletken kumaşlar, iletken kaplamalar ve iletken yapıştırıcılar gibi farklı malzemelerden faydalanılabilir (Castano ve Flatau, 2014).

İletken iplikler gerek bir doku ya da yüzey oluşturmak amacıyla gerekse bağlantı yollarında kullanılmak üzere çokça tercih edilen iletken tekstil ürünlerinden biridir. İletken iplikler kullanılarak yapılan çalışmalar incelendiğinde, iletken ipliklerle ilgili en önemli kriterlerin metal oranı, iletkenlik, esneklik, biyouyumluluk, mekanik dayanım, yıkanabilirlik, makinede işlenebilirlik özellikleri olduğu görülmektedir (Rattfält ve ark., 2007; Stoppa ve Chiolerio, 2014; Linz ve ark., 2005; Linz ve ark., 2006). Bu kriterlere ilave edilmesi gereken bir diğer kriter de fiyat kriteridir.

Günümüz koşullarında seçeneklerin giderek çoğalması, sistemlerin karmaşıklaşması ve beklentilerin artması sebebiyle karar verme süreçleri daha karmaşık ve zor bir hale gelmektedir. Karar verme süreçlerinde tek bir kriterin bulunduğu durumlarda problem kolaylıkla sonuçlandırılabilmekteyken, kriterler çoğaldıkça bu durum zorlaşmaktadır. Bu nedenle, genellikle birbiriyle çelişen faktörleri analiz etmek ve elde edilen sonuçlara göre en iyi alternatifi seçmek ya da alternatifleri sıralamak, karşıllaş,ırmak veya sınıflamak için çok kriterli karar verme tekniklerinden faydalanılır. Literatürde sıklıkla karşılaşılan çok kriterli karar verme teknikleri; DEMATEL(The Decision Making Trial and Evaluation Laboratory), AHP (Analytic Hierarchy Process), ANP (Analytic Network Process), VIKOR (Vise Kriterijumska Optimizacija I Kompromisno Resenje), TOPSIS (Technique for Order Preference by Similarity to Ideal Solution), MOORA (Ratios Analysis and Reference Point Approach) ve ELECTRE (Elemination and Choice Translating Reality English)'dir (Özdemir, 2018; Akın, 2017).

Değerlendirmede kullanılacak olan çok kriterli karar verme yöntemi seçimi her bir faktör için gerekli bilgi düzeyine göre farklılık göstermekte ve her bir yöntem birbirinden farklı çözüm mantıklarıyla çalışmaktadır. Bu çalışmada DEMATEL (Decision Making Trial and Evaluation Laboratory - Karar verme deneme ve değerlendirme laboratuvarı) yöntemi tercih edilmiştir. DEMATEL metodu matris işlemlerine dayanan matematiksel işlemlerin yapıldığ 1 bir ÇKKV (Çok Kriterli Karar Verme) yöntemidir. Bu yöntem sayesinde kriterler arası ilişkiler sayısal olarak belirlenebilmekte, önem ve öncelikleri tespit edilebilmektedir. Ayrıca kriterlerin birbirlerini ne ölçüde etkiledikleri ya da birbirleri üzerinde herhangi bir etkiye sahip olup olmadıkları bu yöntem sayesinde öğrenilebilmektedir. Böylelikle diğer kriterleri yüksek oranda etkileme gücüne sahip olan kriterle ilgili iyileştirmeler yapılarak paralel olarak diğer kriterlerin de iyileştirilebilmesine olanak sağlanabilmektedir (Eroğlu, 2014; Özdemir, 2018).

Bu çalışmada, iletken iplik alımında etkili olduğu düşünülen bu kriterler arasındaki ilişkilerin belirlenmesi için "Çok Kriterli Karar Verme Yöntemleri”nden "DEMATEL” yöntemi kullanılmış ve kriterlere ait öncelik sırası tespit edilmiştir. 


\section{Materyal ve Metot}

Çalışma kapsamında öncelikli olarak iletken iplik alımında etkili 8 adet kriter belirlenmiştir. Bu kriterler; metal oranı, iletkenlik, esneklik, biyouyumluluk, mekanik dayanım, yıkanabilirlik, makinede işlenebilirlik ve fiyattır.

Ardından sektörde aktif olarak çalışmakta olan ve iletken iplik alım kararında etkili 10 uzmana kriterleri içeren bir form mail yoluyla gönderilerek kriterleri DEMATEL ikili karşılaştırma ölçeğine göre değerlendirmeleri istenmiştir. Uzmanlar tarafindan doldurulmuş formlardan elde edilen matrisler DEMATEL yöntemi yardımıyla değerlendirilerek kriterler arasındaki etki derecesi ve kriter ağıllıkları belirlenip kriterlerin önem derecelerine göre sıralanması gerçekleştirilmiştir.

Çalışmada gerekli hesaplamaların yapılabilmesi için Microsoft ${ }^{\circledR}$ Excel programının 16.16.14 sürümü kullanılmıştır.

\subsection{DEMATEL Yöntemi}

DEMATEL, bir yapısal modeldeki karmaşık faktörler arasındaki nedensellik ilişkisini kuran ve analiz eden kapsamlı bir yöntemdir (Karaoğlan, 2016). 1972 ve 1976 yılları arasında Cenevre Battelle Memorial Enstitüsü, Bilim ve İnsan İlişkileri programı tarafından geliştirilmiştir (Eroğlu, 2014). Bu yöntemde, yapısal bir modelin düzenlenmesi için uzmanların bilgisi kullanılır (Karaoğlan, 2016). DEMATEL yöntemi sayesinde kriter ağırlıkları belirlenebilmekte, bu kriterler önem derecelerine göre sıralanabilmekte ve kriterler arasındaki etki derecesi ölçülebilmektedir.

Kriter ağırlıklarını belirlemek için uygulanacak olan DEMATEL yönteminde basamaklar sırası ile aşağıdaki adımları takip eder:

1. Adım: Problemin Tanımlanması: DEMATEL yönteminin ilk aşaması, problemin tespit edildikten sonra net bir şekilde tanımlanmasıdır (Özdemir, 2018).

2. Adım: Kriterlerin Belirlenmesi: $\mathrm{Bu}$ aşamada, ilişkilerin en doğru şekilde incelenmesi ve tespit edilebilmesi için, problemin çözümünde gerekli olan tüm kriterlerin eksiksiz bir şekilde tespit edilmesi gerekmektedir (Özdemir, 2018).

3. Adım: Direkt İlişsi Matrisinin Oluşturulması: Kriterler arasındaki ilişsiler, Tablo 1'deki ikili karşılaştırma ölçeği kullanılarak uzman grup tarafından belirlenmektedir. Puanlamalar 0-4 aralığında yapılmaktadır. Verilen puanlar, bir kriterin diğerini hangi ölçüde etkilediğini göstermektedir.

Tablo 1: İkili Karşılaştırma Ölçeği

\begin{tabular}{c|c}
\hline Sayısal Değer & Tanım \\
\hline 0 & Etkisiz \\
\hline 1 & Düš̈k Etki \\
\hline 2 & Orta Derecede Etki \\
\hline 3 & Yüksek Derecede Etki \\
\hline 4 & Çok Yüksek Derecede Etki \\
\hline
\end{tabular}

Kriterleri değerlendiren uzman sayısı birden fazla ise, puanların aritmetik ortalaması alınır. Ardından elde edilen ortalama değerler matrise yerleştirilir ve köşegen değerleri "0" olan asimetrik bir matris elde edilir. Bu elde ettiğimiz matrise ortalama direkt ilişki matrisi $(\mathrm{X})$ adı verilir.

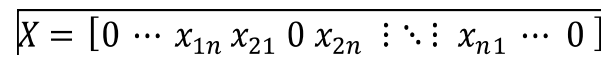

4. Adım: Direkt İlişki Matrisinin Normalizasyonu: Direkt ilişki matrisinin elde edilmesinden sonra eşitlik 1'de görüldüğü gibi her bir satır ve sütun toplamının en büyüğü bulunur.

$$
s=\max \left(\max \sum_{j=1}^{n} x_{i j}, \sum_{i=1}^{n} x_{i j}\right)
$$

Ardından matrisin her bir elemanı "s" değerine bölünerek normalleştirilmiş direkt ilişki matrisi (D) oluşturulur.

$$
D=\frac{x}{s}
$$

5. Adım: Eşitlik 3’te de görüldüğü üzere, D matrisi birim matristen çıkarılır, tersi alınır ve tekrar D matrisi ile çarpılır.

$$
\begin{gathered}
\overline{D+D^{2}+D^{3}+\cdots+D^{H}} \\
F=D+D^{2}+D^{3}+\cdots+D^{H}=D(1-D)^{-1}
\end{gathered}
$$

Böylelikle toplam ilişki matrisi (F) elde edilir.

6. Adım: Kriterler Arası İlişkilerin Tespit Edilmesi: Etkileyen ve etkilenen faktör gruplarının belirlenmesi için, toplam iliş̧ki matrisinin (F) satır (R) ve sütun (C) toplamları bulunur. Elde edilen bu değerler kullanılarak, kriterlere ait önem ve etki durumlarının daha net bir şekilde görülüp incelenebilmesi için nedensel diyagram oluşturulur.

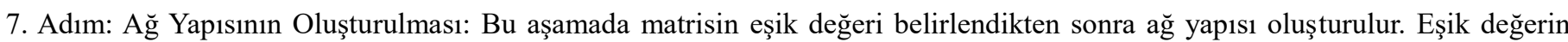
üzerindeki kriterler etkileyen olarak belirlenir ve ağ yapısında etki yönü ok ile belirtilir. Oklar, etkileyenden etkilenene doğru oluşur. 
Eşik değer uzmanlar tarafından belirlenebilir. Bunun mümkün olmaması durumunda toplam ilişki matrisinin (F) ortalaması alınarak da belirlenebilir.

8. Adım: Kriter ağırlıklarının elde edebilmek için, R+C ‘nin karesi ile R-C’nin karesinin toplamı kök içerisine alınır.

$$
W_{i a}=\sqrt{(R+C)^{2}+(R-C)^{2}}
$$

Ardından her bir ağırlık, ağırlıkların toplamına bölünür.

$$
W_{i}=\frac{W_{i a}}{\sum_{i=1}^{n} W_{i a}}
$$

Böylelikle kriter ağırlıkları bulunmuş olur (Karaoğlan, 2016).

\section{Araştırma Sonuçları ve Tartışma}

\subsection{Bulgular}

Çalışma kapsamında uzmanların değerlendirmelerini içeren 10 adet matris elde edilmiştir. Elde edilen bu matrislerdeki puanların aritmetik ortalamaları alınarak Tablo 2'de yer alan ortalama direkt ilişki matrisi (X) elde edilmiştir.

Tablo 2. Ortalama Direkt İlişki Matrisi (X)

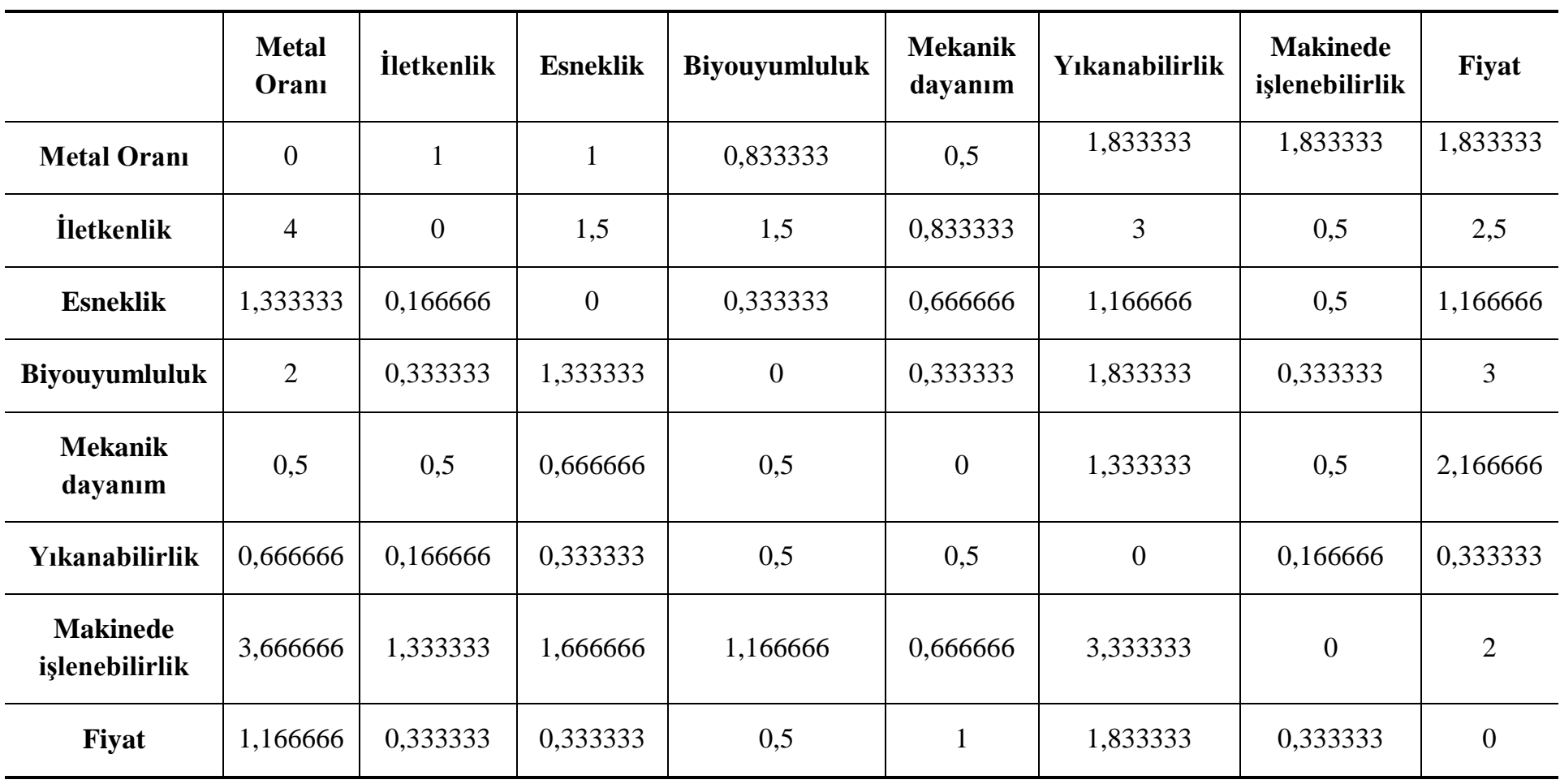

Ortalama direkt ilişki matrisinin elde edilmesinden sonra eşitlik 1 kullanılarak her bir satır ve sütun toplamının en büyüğü (s) bulunmuştur. Ardından matrisin her bir elemanı eşitlik 2'de görüldüğü gibi “s” değerine (14,33) bölünerek Tablo 3 'teki normalize direkt ilişki matrisi (D) oluşturulmuştur. 
Avrupa Bilim ve Teknoloji Dergisi

Tablo 3. Normalize Direkt İlişki Matrisi (D)

\begin{tabular}{c|c|c|c|c|c|c|c|c}
\hline & $\begin{array}{c}\text { Metal } \\
\text { Oranı }\end{array}$ & İletkenlik & Esneklik & Biyouyumluluk & $\begin{array}{c}\text { Mekanik } \\
\text { dayanım }\end{array}$ & Yıkanabilirlik & $\begin{array}{c}\text { Makinede } \\
\text { işlenebilirlik }\end{array}$ & Fiyat \\
\hline Metal Oranı & 0 & 0,070 & 0,070 & 0,058 & 0,035 & 0,128 & 0,012 & 0,058 \\
\hline İletkenlik & 0,279 & 0 & 0,105 & 0,105 & 0,058 & 0,209 & 0,035 & 0,174 \\
\hline Esneklik & 0,093 & 0,012 & 0 & 0,023 & 0,047 & 0,081 & 0,035 & 0,081 \\
\hline Biyouyumluluk & 0,140 & 0,023 & 0,093 & 0 & 0,023 & 0,128 & 0,023 & 0,209 \\
\hline $\begin{array}{c}\text { Mekanik } \\
\text { dayanım }\end{array}$ & 0,035 & 0,035 & 0,047 & 0,035 & 0 & 0,093 & 0,035 & 0,151 \\
\hline $\begin{array}{c}\text { Yıkanabilirlik } \\
\text { Makinede }\end{array}$ & 0,047 & 0,012 & 0,023 & 0,035 & 0,035 & 0 & 0,012 & 0,023 \\
\hline ișlenebilirlik & 0,256 & 0,093 & 0,116 & 0,081 & 0,047 & 0,233 & 0 & 0,140 \\
\hline Fiyat & 0,081 & 0,023 & 0,023 & 0,035 & 0,070 & 0,128 & 0,023 & 0 \\
\hline
\end{tabular}

Normalize direkt ilişki matrisi kullanılarak eşitlik 3 ’teki işlemler gerçekleştirilip toplam ilişki matrisi (F) elde edilmiştir.

Tablo 4. Toplam İlişki Matrisi (F)

\begin{tabular}{c|c|c|c|c|c|c|c|c}
\hline & $\begin{array}{c}\text { Metal } \\
\text { Oranı }\end{array}$ & İletkenlik & Esneklik & Biyouyumluluk & $\begin{array}{c}\text { Mekanik } \\
\text { dayanım }\end{array}$ & Yıkanabilirlik & $\begin{array}{c}\text { Makinede } \\
\text { işlenebilirlik }\end{array}$ & Fiyat \\
\hline Metal Oranı & 0,077 & 0,089 & 0,107 & 0,091 & 0,067 & 0,206 & 0,029 & 0,125 \\
\hline İletkenlik & 0,399 & 0,056 & 0,183 & 0,171 & 0,125 & 0,374 & 0,067 & 0,295 \\
\hline Esneklik & 0,146 & 0,035 & 0,034 & 0,052 & 0,073 & 0,152 & 0,048 & 0,131 \\
\hline Biyouyumluluk & 0,223 & 0,057 & 0,139 & 0,046 & 0,072 & 0,238 & 0,045 & 0,276 \\
\hline $\begin{array}{c}\text { Mekanik } \\
\text { dayanım }\end{array}$ & 0,107 & 0,058 & 0,083 & 0,068 & 0,035 & 0,175 & 0,051 & 0,205 \\
\hline Yıkanabilirlik & 0,077 & 0,024 & 0,043 & 0,050 & 0,048 & 0,041 & 0,019 & 0,057 \\
\hline $\begin{array}{c}\text { Makinede } \\
\text { işlenebilirlik }\end{array}$ & 0,389 & 0,144 & 0,198 & 0,154 & 0,116 & 0,401 & 0,035 & 0,267 \\
\hline Fiyat & 0,134 & 0,045 & 0,058 & 0,064 & 0,094 & 0,192 & 0,037 & 0,057 \\
\hline
\end{tabular}

A $\breve{g}$ yapısının oluşturulması aşamasında, toplam ilişki matrisinin $(F)$ ortalaması alınarak eşik değer $(0,12115625)$ belirlenmiştir. Tablo 5'te Toplam İlişki Matrisinde eşik değerini aşan hücreler koyu renkle gösterilmiştir. Bu sonuçlar yorumlanırken; satır elemanlarının, sütun elemanları üzerinde etkisi olduğu söylenerek ifade edilmiştir. 
European Journal of Science and Technology

Tablo 5. Toplam Illişki Matrisinde Eşik Değerini Aşan İlişkiler

\begin{tabular}{c|c|c|c|c|c|c|c|c}
\hline & $\begin{array}{c}\text { Metal } \\
\text { Oranı }\end{array}$ & İletkenlik & Esneklik & Biyouyumluluk & $\begin{array}{c}\text { Mekanik } \\
\text { dayanım }\end{array}$ & Yıkanabilirlik & $\begin{array}{c}\text { Makinede } \\
\text { işlenebilirlik }\end{array}$ & Fiyat \\
\hline Metal Oranı & 0,085 & 0,094 & 0,114 & 0,096 & 0,072 & 0,219 & 0,031 & 0,134 \\
\hline İletkenlik & 0,422 & 0,061 & 0,195 & 0,182 & 0,134 & 0,399 & 0,072 & 0,314 \\
\hline Esneklik & 0,155 & 0,038 & 0,038 & 0,056 & 0,078 & 0,162 & 0,050 & 0,139 \\
\hline Biyouyumluluk & 0,237 & 0,062 & 0,148 & 0,051 & 0,077 & 0,254 & 0,049 & 0,291 \\
\hline $\begin{array}{c}\text { Mekanik } \\
\text { dayanım }\end{array}$ & 0,116 & 0,061 & 0,088 & 0,072 & 0,039 & 0,187 & 0,054 & 0,216 \\
\hline Yıkanabilirlik & 0,082 & 0,026 & 0,045 & 0,052 & 0,051 & 0,045 & 0,021 & 0,061 \\
\hline $\begin{array}{c}\text { Makinede } \\
\text { işlenebilirlik }\end{array}$ & 0,413 & 0,153 & 0,211 & 0,164 & 0,124 & 0,428 & 0,039 & 0,286 \\
\hline Fiyat & 0,143 & 0,048 & 0,062 & 0,068 & 0,099 & 0,203 & 0,039 & 0,063 \\
\hline
\end{tabular}

Tablo 5’teki sonuçlar, hangi kriterin diğer kriterlerden hangisinin ya da hangilerinin üzerinde etkisinin olduğunu göstermektedir. Her bir kriterin hangi kriterler üzerinde etkisi olduğuna yönelik yorumlar şu şekildedir:

- Metal oranı kriteri yıkanabilirlik ve fiyat kriterleri üzerinde etkilidir.

- İletkenlik kriteri; metal oranı, esneklik, biyouyumluluk, mekanik dayanım, yıkanabilirlik ve fiyat kriterleri üzerinde etkilidir.

- Esneklik kriteri; metal oranı, yıkanabilirlik ve fiyat kriterleri üzerinde etkilidir.

- Biyouyumluluk kriteri; metal oranı, esneklik, yıkanabilirlik ve fiyat kriterleri üzerinde etkilidir.

- Mekanik dayanım kriteri; yıkanabilirlik ve fiyat kriterleri üzerinde etkilidir.

- Yikanabilirlik kriterinin herhangi bir kriter üzerinde etkisi bulunmamaktadır.

- Makinede işlenebilirlik kriteri; metal oranı, iletkenlik, esneklik, biyouyumluluk, mekanik dayanım, yıkanabilirlik ve fiyat kriterleri üzerinde etkilidir.

- Fiyat kriteri; metal oranı ve yıkanabilirlik kriterleri üzerinde etkilidir.

Kriter arası ilişkilerin tespit edilebilmesi amacıyla eşitlik 4 ve 5 kullanılarak Tablo 6'da görülen kriterler arası ilişkiler ve etkiler ile kriter ağırlıkları tespit edilmiştir. 
Tablo 6. Kriterlerin Önemleri ve Birbirleri Arasındaki Etki Durumları

\begin{tabular}{c|c|c|c|c|c|c|c}
\hline & $\mathbf{R}$ & $\mathbf{C}$ & $\mathbf{R}+\mathbf{C}$ & $\mathbf{R - C}$ & $\sqrt{(R+C)^{2}+(R-C)^{2}}$ & $\begin{array}{c}\text { Kriter } \\
\text { Ağırlıkları } \\
(\mathbf{w})\end{array}$ & $\begin{array}{c}\text { Kriter } \\
\text { Oncelikleri }\end{array}$ \\
\hline Metal Oranı & 0,791 & 1,552 & 2,343 & $-0,761$ & 1,257775815 & 0,1160802028 & $\mathbf{4}$ \\
\hline Illetkenlik & 1,67 & 0,508 & 2,178 & 1,162 & 1,827566688 & 0,1686662355 & $\mathbf{2}$ \\
\hline Esneklik & 0,671 & 0,845 & 1,516 & $-0,174$ & 1,158447237 & 0,1069131626 & $\mathbf{7}$ \\
\hline Biyouyumluluk & 1,096 & 0,696 & 1,792 & 0,400 & 1,480540442 & 0,1366391631 & $\mathbf{3}$ \\
\hline $\begin{array}{c}\text { Mekanik } \\
\text { dayanım }\end{array}$ & 0,782 & 0,630 & 1,412 & 0,152 & 1,250599856 & 0,1154179332 & $\mathbf{5}$ \\
\hline Yıkanabilirlik & 0,359 & 1,779 & 2,138 & $-1,420$ & 0,8473488066 & 0,078201870 & $\mathbf{8}$ \\
\hline $\begin{array}{c}\text { Makinede } \\
\text { işlenebilirlik }\end{array}$ & 1,704 & 0,331 & 2,035 & 1,373 & 1,846076921 & 0,170374546 & $\mathbf{1}$ \\
\hline Fiyat & 0,681 & 1,413 & 2,094 & $-0,732$ & 1,167047557 & 0,1077068866 & 6 \\
\hline
\end{tabular}

Tablo 6'daki kriter ağırlıkları öncelik derecesine göre sıralanmıştır. Makinede işlenebilirlik sistem içerisindeki en önemli kriter olmuştur. En önemsiz kriter ise \%7,8 ağırlığı ile yıkanabilirlik kriteridir sonucuna varılmıştır.

Kriterlere ait önem ve etki durumlarının daha net bir şekilde görülüp incelenebilmesi için Şekil 1'de yer alan iletken iplik alım kriterleri nedensel diyagramı oluşturulmuştur.

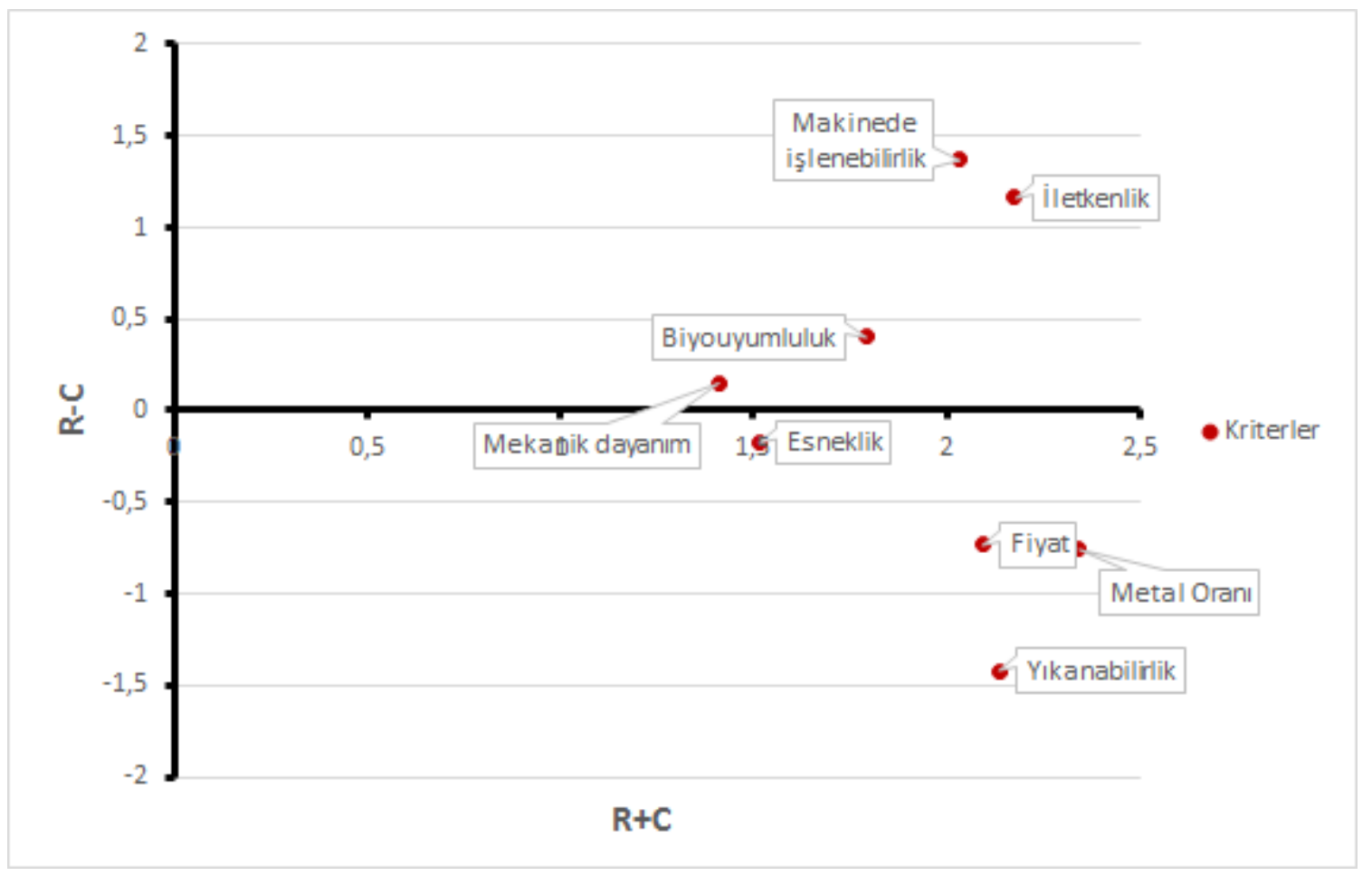

Şekil 1. Nedensel Diyragram

Nedensel diyagramda R-C için sıfır çizgisinin altında kalan kriterler; esneklik, metal oranı, yıkanabilirlik ve fiyat diğer kriterler tarafından etkilenen kriterlerdir. Sıfir çizgisinin üstünde kalan değerler olan biyouyumluluk, mekanik dayanım, makinede işlenebilirlik ve iletkenlik ise, diğer kriterleri baskın bir şekilde etkileyen kriterlerdir. $\mathrm{R}+\mathrm{C}$ ekseninde ise, sıfirdan uzaklaştıkça kriterlerin önemi artmaktadır. Kriterlerin öncelik derecelerindeki önem sıralamaları nedensel diyagram yardımıla daha görsel hale gelmektedir. Örneğin; nedensel diyagramda $\mathrm{R}+\mathrm{C}$ ekseninde sıfirdan en uzakta olan kriter yani önem derecesi en düşük olan değer y1kanabilirlik olarak görülmektedir. 


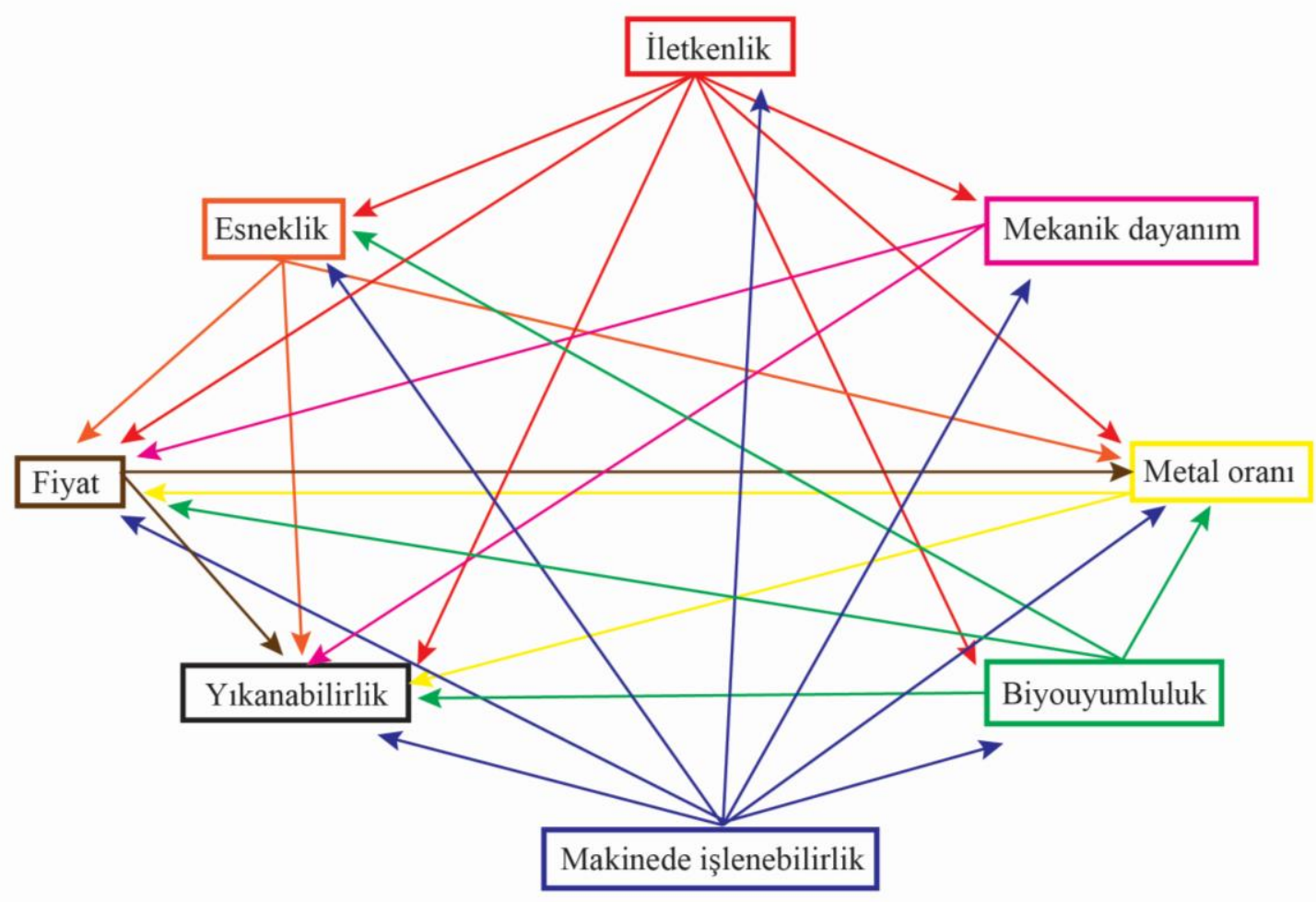

Şekil 2. İletken İplik Alım Kriterleri Ăg Yapısı

Şekil 2'deki ağ yapısında da nedensel diyagramda çıkan sonuçlara paralel olarak etkileyen ve etkilenen kriterler görülmektedir. A $\breve{g}$ yapısında okların baktığı yöndeki kriterler etkilenen kriterlerdir. Aynı zamanda okların çıkış noktasında yer alan kriterler de diğer kriterleri etkileyen kriterlerdir.

\section{Sonuç}

$\mathrm{Bu}$ çalışmada iletken iplik alımında etkili kriterler arasındaki ilişkilerin DEMATEL yöntemi ile belirlenmesi amaçlanmıştır. Bu amaç doğrultusunda iletken iplik alım kararında etkili 10 uzmanın görüşleri DEMATEL yöntemine göre değerlendirilmiştir.

Kriter ağırlıkları öncelik derecesine göre sıralandığında; \%17 kriter ağırlı̆̆ı ile makinede işlenebilirlik sistem içerisindeki en önemli kriter olmuştur. Bu kriteri sırasıyla iletkenlik $(\% 16,86)$, biyouyumluluk $(\% 13,66)$, metal oranı $(\% 11,60)$, mekanik dayanım $(\% 11,54)$, fiyat $(\% 10,77)$ ve esneklik $(\% 10,69)$ kriterleri takip etmektedir. En önemsiz kriter ise \%7,8 ağırlığı ile yıkanabilirlik kriteridir.

Ağ yapısı incelenerek kriterlerin birbirini etkileme durumlarına bakıldığında; makinede işlenebilirlik kriterinin en çok kriteri etkilediği görülürken bu kriter hiçbir kriterden etkilenmemektedir. Yıkanabilirlik kriterinin hiçbir kriter üzerinde etkisi yokken, tüm kriterlerden etkilendiği sonucuna ulaşılmıştır. İletken iplik kullanarak üretim yapan işletmelerin önceliği iplik ile istedikleri formda yapılar üretebilmek olduğu için makinede işlenebilirlik kriteri beklendiği gibi en önemli kriter olarak tespit edilmiştir. Y1kanabilirlik kriteri ise aslında elektronik tekstil ürünleri için öenmli bir kriter olmasına rağmen, ürün henüz ticarileşme aşamasında olması ve tüketici ile buluşmaması sebebiyle şimdilik üreticiler tarafından göz ardı edilmektedir.

$\mathrm{Bu}$ sonuçlardan yola çıkılarak, iletken iplik üreticilerinin müşterilerinin beklentilerini ve önceliklerini anlamaları sağlanabilir. $\mathrm{Bu}$ çalışma, iletken iplik üreticilerinin piyasayı analiz ederek daha efektif bir ürün yelpazesi sunmalarında yol gösterici olacaktır.

\section{Kaynakça}

1. Yetmen, G. (2017). Giyilebilir Teknoloji. Ulakbilge, 5 (9), 275-289.

2. Lukowicz, P. (2008). Wearable computing and artificial intelligence for healthcare applications. Artificial Intelligence in Medicine, 42, 95-98.

3. Wagner, S., Bonderover, E., Jordan, W. B. ve Sturm, J. C. (2002). Electrotextiles: concepts and challenges. International Journal of High Speed Electronics and Systems, 12 (02), 391-399.

4. Castano, L. M. ve Flatau, A. B. (2014). Smart fabric sensors and e-textile technologies: a review. Smart Materials and Structures, 23 (5), 053001.

5. Rattfält, L., Lindén, M., Hult, P., Berglin, L., \& Ask, P. (2007). Electrical characteristics of conductive yarns and textile electrodes for medical applications. Medical \& Biological Engineering \& Computing, 45(12), 1251-1257. 
6. Stoppa, M., \& Chiolerio, A. (2014). Wearable electronics and smart textiles: a critical review. Sensors, 14(7), 11957-11992.

7. Linz, T., Kallmayer, C., Aschenbrenner, R., \& Reichl, H. (2005, October). Embroidering electrical interconnects with conducti ve yarn for the integration of flexible electronic modules into fabric. In Wearable Computers, 2005. Proceedings. Ninth IEEE International Symposium on (pp. 86-89). IEEE.

8. Linz, T., Kallmayer, C., Aschenbrenner, R., \& Reichl, H. (2006, April). Fully integrated EKG shirt based on embroidered electrical interconnections with conductive yarn and miniaturized flexible electronics. In Wearable and Implantable Body Sensor Networks, 2006. BSN 2006. International Workshop on (pp. 4-pp). IEEE.

9. Akın, N. G. (2017). İşletme Bölümü Öğrencilerinin Meslek Seçimini Etkileyen Faktörlerin Bulanık Dematel Yöntemi ile Değerlendirilmesi. Uluslararası Yönetim İktisat ve İşletme Dergisi, 13(4), 873-890.

10. Eroğlu, Ö. (2014). Bakım/Onarım Alternatiflerinin Bulanık Dematel ve SMAA-2 Yöntemleriyle Değerlendirilmesi. Kara Harp Okulu Savunma Bilimleri Enstitüsü, Yayımlanmamış Yüksek Lisans Tezi. Ankara.

11. Karaoğlan, S. (2016). Dematel ve Vikor Yöntemleriyle Dış Kaynak Seçimi: Otel İşletmesi Örneği. Akademik Bakış Uluslararası Hakemli Sosyal Bilimler Dergisi, (55), 9-24.

12. Özdemir, M. (Ed.) (2018). Çok Kriterli Karar Verme Yöntemleri-Açıklamalı ve Karşılaştırmalı Sağlık Bilimleri Uygulamaları ile. Ankara: Nobel. 